\title{
Índice laterítico do Granito Serra Dourada, Goiás, Brasil - Áreas potenciais para depósito de Terras Raras
}

\author{
Lucy Takehara1 (lucy.chemale@cprm.gov.br) \\ Cláudio Gerheim Porto² (porto@geologia.ufrj.br) \\ Edgar Romeo Figueiredo Iza ${ }^{1}$ (edgar.iza@cprm.gov.br) \\ Guilherme F. da Silva ${ }^{1}$ (guilherme.ferreira@cprm.gov.br) \\ Luiz Gustavo Rodrigues Pinto1 (luiz.pintp@cprm.gov.br)
}

${ }^{1}$ Serviço Geológico do Brasil - CPRM; ${ }^{2}$ Universidade Federal do Rio de Janeiro - UFRJ.

\begin{abstract}
The lateritic index (LI) has been applied to identify new areas with the potential to contain rare earth elements (REE) ion adsorption deposit (IAD) associated with the Serra Dourada granite, similar to those found in the south part of this granite. This granite has high contents of $\sum R E E$ that are distributed in different types of minerals, which upon weathering release the REE into the laterite profile. Another important aspect is the degree of weathering of this laterite profile and the percolating fluids that lead to the retention of REE in the profile, mainly adsorbed on clay minerals. This results in REE enrichment associated with the clay layer. The correlation of gamma spectrometry and altimetry data indicated that the $\mathrm{LI}$ in this granitic body is uneven and, is dependent on the intensity of the surface denudation. The higher $\mathrm{LI}$ is identified in the southern part of this body, where a supergene REE deposit has been identified and is under development. However, this higher $L I$ is also found in other parts of this granite, which could represent new potential areas to be explored.
\end{abstract}

Keywords: Rare earth elements, lateritic profile, clay ion adsorption deposit.

Palavras-chave: Elementos Terras Raras, perfil laterítico, depósitos íons adsorvidos em argila.

\section{INTRODUÇÃO}

Os elementos terras raras (ETR) são considerados críticos para muitos países tanto pelo aumento da demanda quanto pela concentração de sua produção por um país (BRASIL, 2010; EUROPEAN COMISSION, 2020). No entanto, os ETR considerados críticos são Nd, Dy, Eu, Tb e $\mathrm{Y}$, de maior interesse econômico, pois possuem as maiores demandas na indústria de alta tecnologia e de energia renovável e limpa (EUROPEAN COMISSION, 2020).

Os depósitos de ETR podem ser encontrados em diversos ambientes geológicos (CHAKHMOURADIAN; ZAITEV, 2012). Estão principalmente associados às rochas ígneas ou ambientes secundários e podem ser extraídos como minério principal ou como subproduto. No Brasil são conhecidos diversos depósitos (TAKEHARA et al., 2015), sendo que os mais importantes atualmente são os de Araxá (MG) com extração de ETR como subproduto do minério de nióbio pela Companhia Brasileira de Metalurgia e Mineração - CBMM; e o projeto mineiro em implantação da Mineração Serra Verde no granito Serra Dourada em Minaçu (GO) (TERRAS..., 2013).

Os depósitos de ETRP mais importantes são associados aos perfis lateríticos desenvolvidos sobre rochas graníticas (BAO; ZHAO, 2008); (SANEMATSU; WATANABE, 2016). Esses depósitos são conhecidos como depósitos de ETR adsorvidos em argilas (Ion adsorption deposit - IAD), como os que ocorrem no sul da China, maiores produtores de ETRP. A importância deste tipo de depósito é inquestionável; no entanto, os melhores depósitos em termos de concentrações de ETR críticos, são os depósitos de ETR leves (ETRL) adsorvidos em argilas (GOODENOUGH et al., 2017). 
Na porção sul do Granito Serra Dourada (GSD), situado na província estanífera de Goiás, foi identificado um depósito de ETR adsorvidos em argilas (SANTANA; WALL; BOTELHO, 2015); (PINTO-WARD, 2017); (HERRINGTON et al., 2019). A mineralização de ETR está concentrada no horizonte saprolítico, com os maiores teores na camada argilosa na base deste horizonte, com enriquecimento de 1,5 a 10 vezes em relação à rocha mãe (PINTO-WARD, 2017).

$O$ regolito laterítico ocorre principalmente em regiões associadas ao cinturão intertropical (latitudes entre $30^{\circ} \mathrm{N}$ e $30^{\circ} \mathrm{S}$ ), devido às altas temperaturas e pluviosidade, onde os processos de lateritização são mais efetivos (FREYSSINET et al., 2005). No Brasil, os estudos do regolito laterítico tem se concentrado sobretudo nas regiões norte e centro oeste, devido à presença de extensa cobertura regolítica associa$\mathrm{da}$ a depósitos minerais (e.g. $\mathrm{Al}, \mathrm{Mn}, \mathrm{Fe}, \mathrm{Ni}, \mathrm{Nb}, \mathrm{P}$, $\mathrm{Au}$ ). Estes estudos, normalmente estão focados nos aspectos geoquímicos e mineralógicos dos perfis regolíticos e, de forma secundária, nas informações geofísicas e geocronológicas. Os principais trabalhos de pesquisa desses regolitos que incorporam aerogamaespectrometria, dados altimétricos e de sensoriamento remoto encontram-se também nesta região (e.g. CARRINO et al., 2011; IZA, 2017; IZA; SANTOS; CRUZ FILHO, 2020; PORTO; BRANDÃO; SILVA, 2016).

O principal objetivo deste trabalho é a identificação das áreas de perfis lateríticos bem desenvolvidos, por meio da integração de dados aerogeofísicos e altimétricos no Granito Serra Dourada. Neste trabaIho também será apresentada a descrição sumária do perfil laterítico e respectivos dados de difratometria de raios-x e geoquímica. A identificação dos perfis lateríticos mais espessos poderá indicar outras áreas potenciais de mineralização de ETR neste corpo granítico.

\section{CONTEXTO GEOLÓGICO}

A Província Estanífera de Goiás (PEG) é formada por diversos granitos mineralizados em estanho nos estados de Goiás (MARINI; BOTELHO, 1986), e está inserida na porção central da Província Tocantins (ALMEIDA et al., 1977). Esta unidade geotectônica é composta por três cinturões dobrados (Brasília, Araguaia e Paraguai) formados pela colisão dos blocos cratônicos: Amazônico (oeste), São Francisco (leste) e Paranapanema (sudoeste), dentro da orogenia Brasiliana (DELGADO et al., 2003). A PEG está inserida no cinturão de dobramento Brasília, formada predominantemente por espessa sequência de rochas supracrustais deformadas e metamorfizadas (MARINI; BOTELHO, 1986).

A PEG está dividida em quatro subprovíncias (Rio Paranã, Rio Tocantins, Pirenópolis-Goianésia e Ipameri). Os granitos desta província são caracterizados como intracratônicos, anorogênicos e de idade proterozoica (MARINI; BOTELHO, 1986). Estão relacionados geneticamente com a evolução continental do rifte Araí e ao vulcanismo bimodal contemporâneo (DARDENNE, 2000). Os corpos graníticos desta província apresentam teores anômalos para ETR (MARINI; BOTELHO; ROSSI, 1992).

O Granito Serra Dourada pertencente à subprovíncia Rio Tocantins e, atualmente, na sua porção sul, apresenta o único depósito de ETR da região (Figura 1). É o maior corpo granítico da PEG, alongado de direção NS, cortado por falhas e está circundado pelos metassedimentos do grupo Serra da Mesa (MACAMBIRA, 1983). A mineralização de cassiterita da PEG está relacionada com alterações pós- a tardi-magmáticas (MARINI; BOTELHO, 1986) que influen-
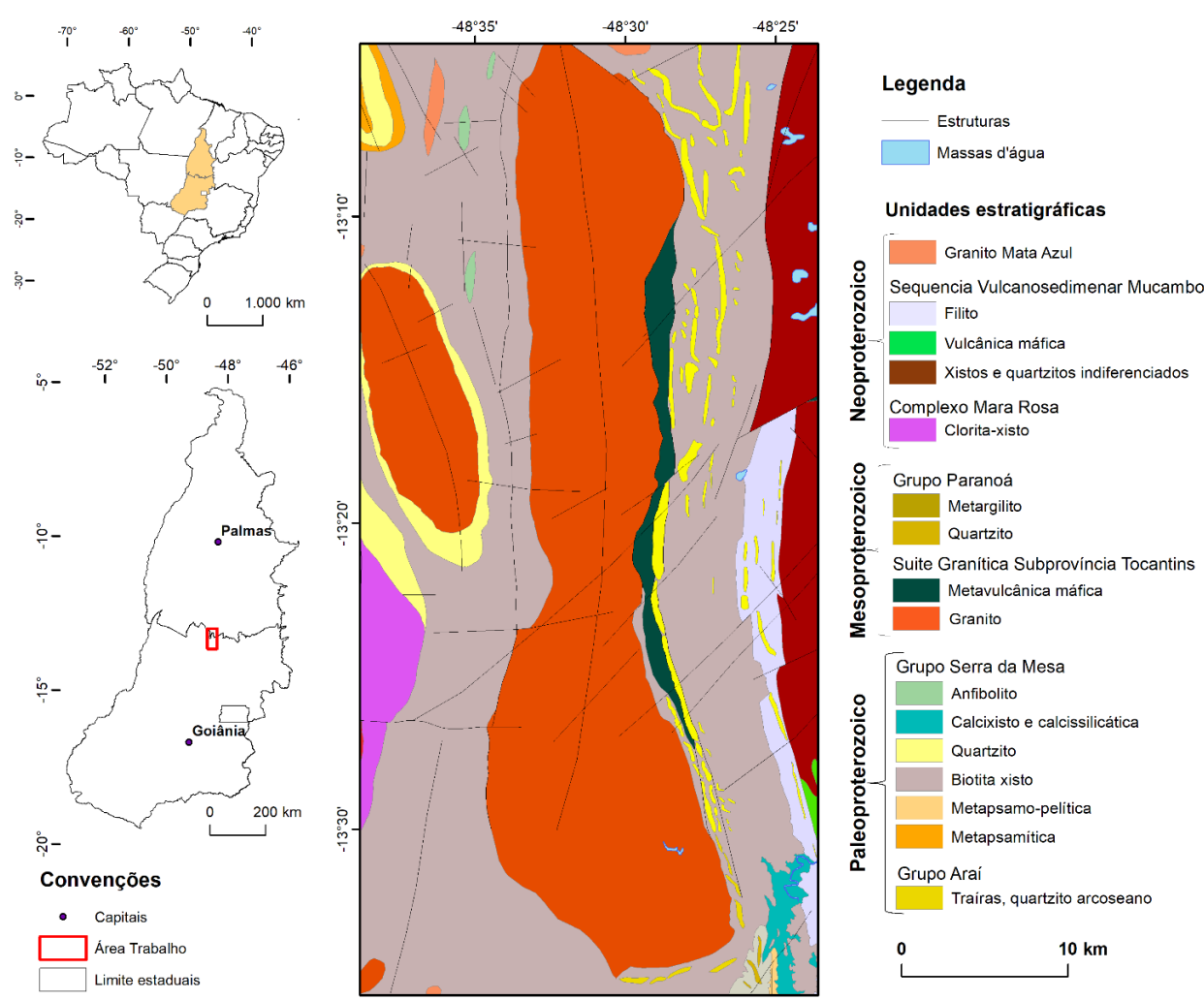

Figura 1 - Mapa geológico simplificado da área de estudo. 
ciaram na mobilidade de ETR e na formação de minerais secundários de ETR (TEIXEIRA; BOTELHO, 2006). Os principais minerais deste granito são monazita, xenotima allanita e bastnaesita (SANTANA; WALL; BOTELHO, 2015). Enquanto que no saprólito os minerais portadores de ETR identificados foram monazita, xenotima e zircão, como resistatos. No entanto, parte dos ETR presentes e com concentrações economicamente viáveis, estão adsorvidos em argilominerais ou em minerais neoformados (PINTO-WARD, 2017).

\section{ÍNDICE LATERÍTICO}

O índice laterítico (IL) é dado pela razão $\left(T h^{*} U\right) / K^{2}$, baseado em dados gamaespectrométricos e representa a relação dos elementos enriquecidos e empobrecidos por processo de intemperismo (CARRINO et al., 2011; IZA, 2017; IZA et al., 2020). O IL pode ser correlacionado com dados de relevo (Figura $2 \mathrm{~A}$ ) e sensoriamento remoto possibilitando a melhor identificação da ocorrência dos perfis lateríticos. Áreas com alto IL sugerem potencial de perfis lateríticos bem desenvolvidos e/ou completos, ou seja, com a presença de crostas lateríticas e latossolos associados. Enquanto que as áreas com baixo índice laterítico indicam perfis lateríticos menos desenvolvidos ou truncados pela erosão (Figura 2B).

Os padrões dos canais eU, eTh e $\mathrm{K}$ no Granito Serra Dourada mostram-se relativamente altos para os três canais, definindo bem a forma e natureza da rocha (granitoide). No que diz respeito ao canal do K, dentro dos limites do corpo, os valores mais baixos tem boa correlação com as áreas de vale. Os maiores valores encontram-se distribuídos nos extremos norte e sul e em algumas porções da parte central. No caso do eU, os menores valores são observados na porção norte do corpo; e igualmente ao $\mathrm{K}$ com valores elevados bem distribuídos. O canal eTh apresenta o padrão mais homogêneo dos três elementos avaliados destacando as áreas com valores mais elevados no norte e no sul.

A avaliação do relevo mostra que o corpo Serra Dourada tem expressivo destaque topográfico regional com cotas que podem atingir cerca de 1000 $m$, nas porções sul e extremo norte, enquanto que a superfície regional tem média de $400 \mathrm{~m}$. Apesar disso, mostra-se parcialmente dissecado em especial na sua porção centro-nordeste e extremo sul aonde as cotas chegam a $450 \mathrm{~m}$.

O IL mostra os maiores valores na parte sul do granito Serra Dourada e em algumas porções da parte norte, preferencialmente em cotas acima de 700 $\mathrm{m}$ e com picos de valores parcialmente coincidentes com as cotas acima de $900 \mathrm{~m}$, onde o relevo é dominado por antigas superfícies planas. (Figura 3). $48^{\circ} 30^{\prime} \mathrm{W}$

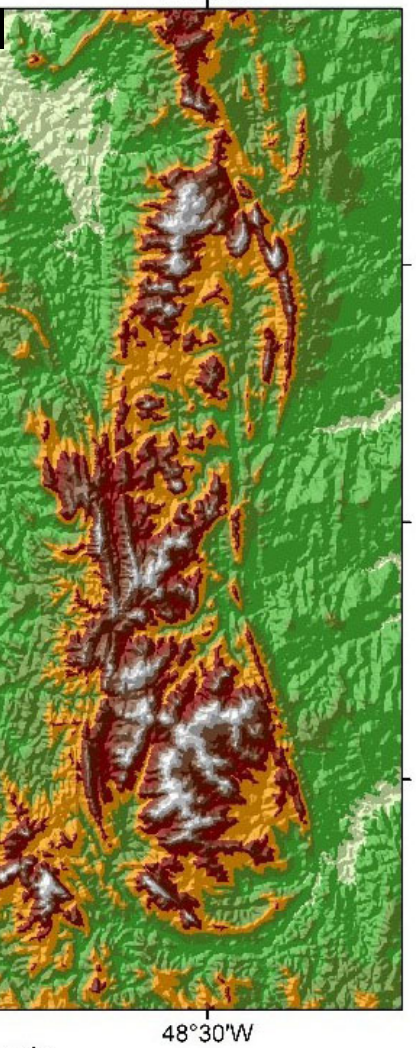

egenda

$300-400$

$400-500$

$500-600$

$600-700$

$700-750$

$750-800$

$800-850$

$850-900$

$900-1125$
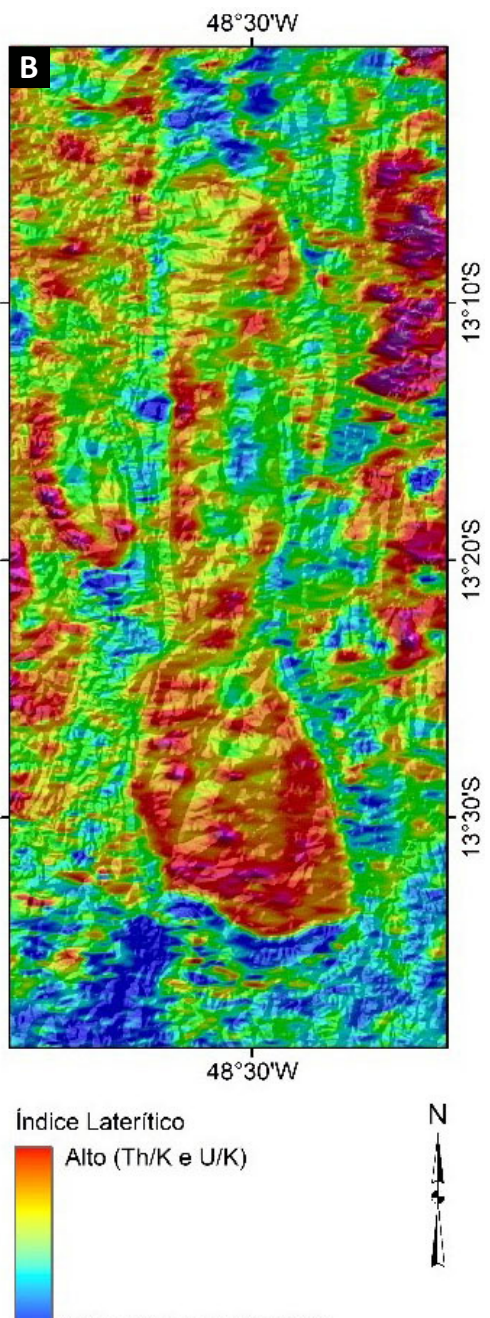

Baixo (Baixo Th/K e U/K)

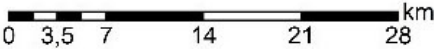

Figura 2 - A) Relevo da área de estudo com foco no granito Serra Dourada. B) Índice laterítico destacando áreas com alto e baixo potencial de ocorrência de perfis lateríticos bem desenvolvidos.

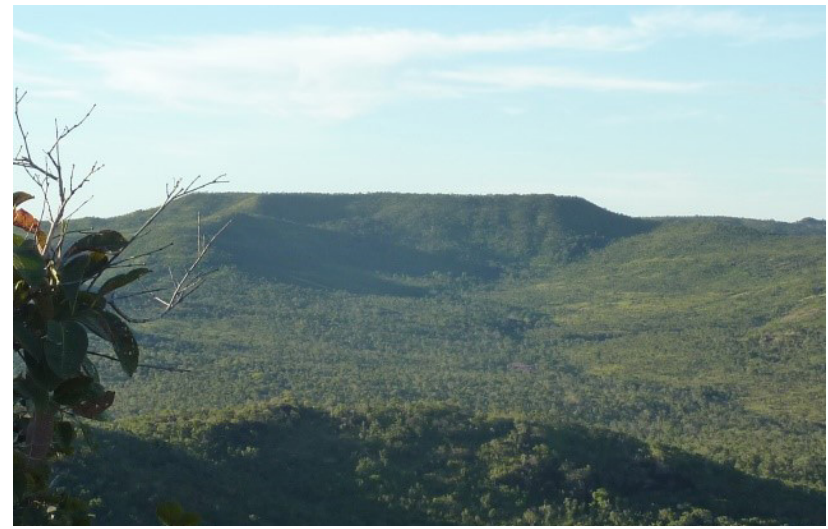

Figura 3 - Aspecto geomorfológico da área do depósito de $T R$, onde apresenta o perfil regolítico mais desenvolvido.

Nas porções mais elevadas, o perfil laterítico está melhor preservado (Figura 4). Nas encostas das escarpas, o perfil está truncado pela erosão, tornando-se quase inexistente nos vales, com frequente exposição do saprólito e da rocha-mãe e predomínio de fragmentos de quartzo no colúvio. A espessura deste perfil pode ter mais de 30 metros como é o caso da área do depósito de ETR da mineração Serra Verde. 
A Figura 5A mostra o gradiente total e os domínios delimitados com alto índice laterítico. Notadamente, no sul do granito Serra Dourada, há pelo menos um domínio com maiores valores relativos de intensidade magnética com sobreposição com altos índices lateríticos e cotas acima de $700 \mathrm{~m}$. As intensidades magnéticas distintas corroboram com a variação composicional deste granito, anfibólio granito na borda e biotita granito no centro (MACAMBIRA, 1983; BILAL, 1991).

Perfil do regolito na região sul do granito Serra Dourada

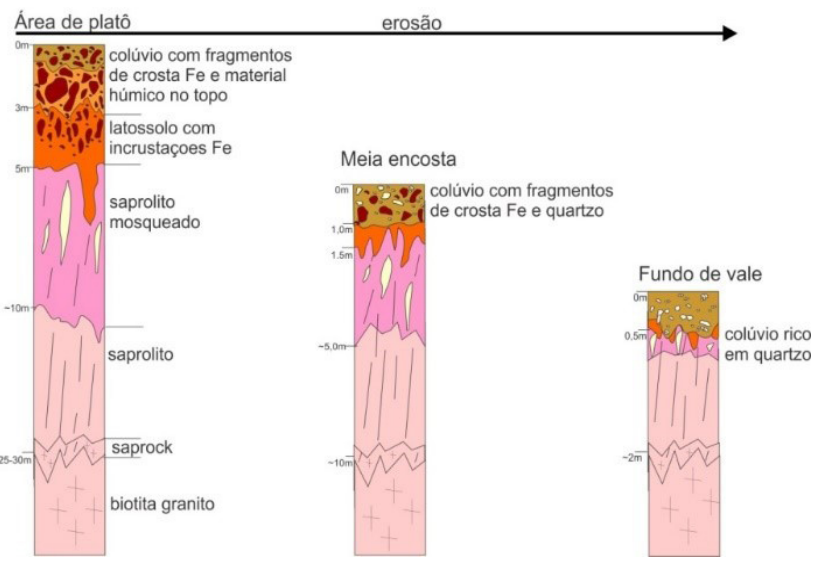

Figura 4 - Perfil intempérico em diferentes níveis da encosta do platô, representação da porção sul do granito Serra Dourada.

A Figura 5B mostra a delimitação de dois domínios principais relacionados aos altos e muito altos valores de IL. A área em vermelho e preto são consideradas com maior potencial para ocorrência de perfis lateríticos bem desenvolvidos (completos). As áreas em preto são as de maiores valores de IL, merecem atenção, devido ao seu maior potencial para enriquecimento supergênico de ETR.

\section{DESCRIÇÃO DA OCORRÊNCIA}

O perfil intempérico pode ser descrito por meio de amostras obtidas de um furo de trado (FD117) realizado em uma área de platô. $O$ furo foi interrompido aos $16 \mathrm{~m}$ de profundidade devido às limitações do equipamento, na zona saprolítica. A descrição do topo para base (metros em profundidade) é apresentada a seguir:

a. $0,0 \mathrm{~m}$ a $2,85 \mathrm{~m}$ - horizonte de colúvio, rico em concreções quartzo-ferruginosas, principalmente na porção basal;

b. 2,85 m a 5,0 $\mathrm{m}$ - horizonte latossólico;

c. $5,0 \mathrm{~m}$ a 7,5 $\mathrm{m}$ - saprólito mosqueado ferruginoso rico em concreções ferruginosas;

d. 7,5 m a $11,5 \mathrm{~m}$ - saprólito mosqueado menos ferruginoso com manchas cauliníticas mais proeminentes; e

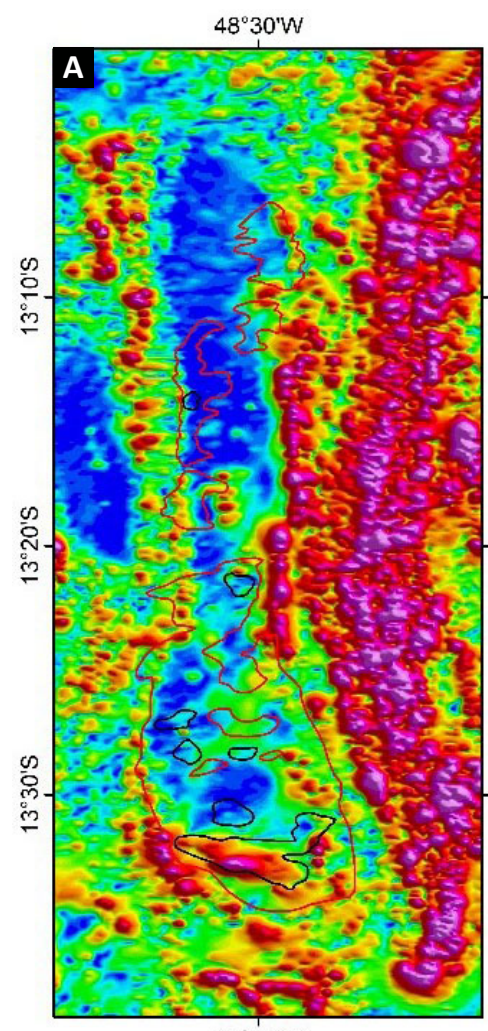

$48^{\circ} 30^{\prime} \mathrm{W}$

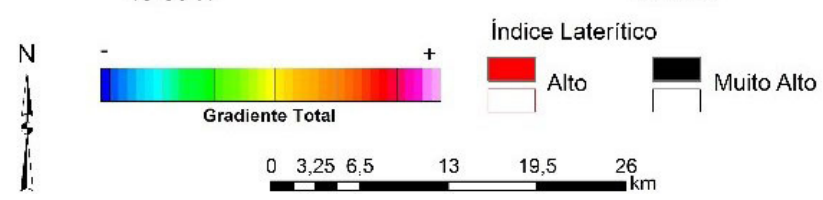

Figura 5 - A) Áreas delimitadas com alto IL sobrepostas ao Gradiente total. B) Áreas prioritárias de estudo do regolito e sua relação com o enriquecimento supergênico. e. $11,5 \mathrm{~m}$ a $16,0 \mathrm{~m}$ - predomina saprólito homogeneamente ferruginoso.

\section{DIFRATOMETRIA DE RAIOS-X E GEOQUÍMICA}

Os principais minerais identificados por difratometria de raios- $X$ são quartzo, caulinita, gibbsita e hematita/ goethita (Figura 6). A passagem da base do colúvio ferruginoso para o saprólito mosqueado é marcada pela gibbsita que passa a ocorrer apenas em traços até desaparecer por completo no saprólito mosqueado caulinítico. A presença de goethita é mais marcante na base do colúvio onde ocorrem grandes acumulações de crosta ferruginosa.

Os resultados geoquímicos do furo mostram que o Fe ilustra bem as variações do regolito (Figura 7A). Os valores mais elevados, da ordem de 15 a $30 \%$ de $\mathrm{Fe}_{2} \mathrm{O}_{3}$, são associados ao colúvio ferruginoso especialmente nas suas porções mais inferiores e com abundantes concreções ferruginosas. Os latossolos são também ricos, com valores em torno de $10 \%$ de $\mathrm{Fe}_{2} \mathrm{O}_{3}$. No saprólito mosqueado os teores de Fe diminuem sendo que a porção ferruginosa superior é mais rica do que a porção caulinítica inferior. Abaixo, no saprólito ferruginoso, os teores de Fe aumentam novamente. 


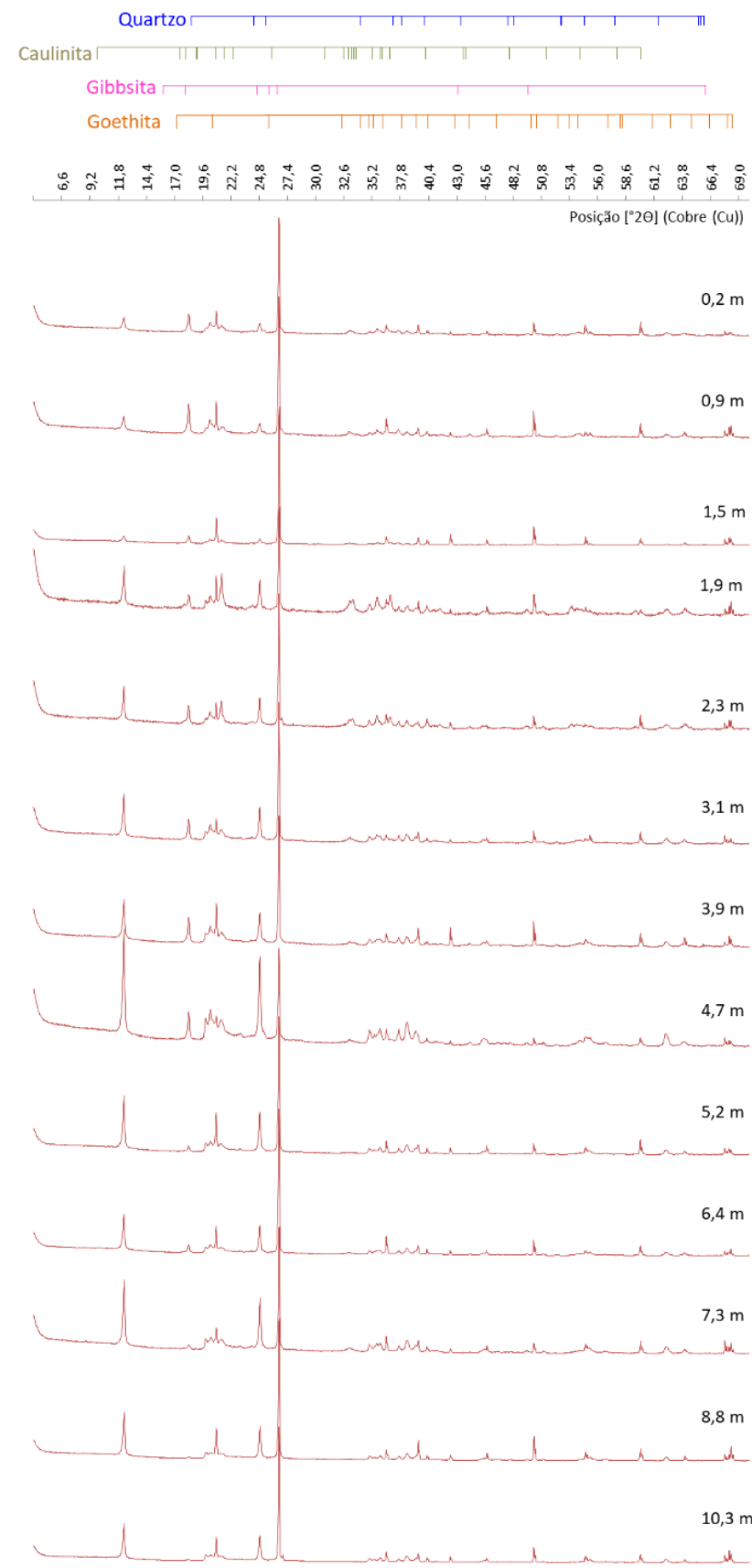

Figura 6 - Análise mineralógica por DRX das amostras do furo de trado FD117, mostra variação na distribuição mineralógica com a profundidade.

Os teores dos metais alcalinos e alcalinos terrosos são em geral muito baixos devido à intensa lixiviação, porém o $\mathrm{K}$ apresenta um leve enriquecimento no intervalo de 6 a $11 \mathrm{~m}$, coincidente com o saprólito mosqueado ferruginoso e caulinítico (Figura 7B). Este intervalo é também enriquecido em ETRL (ex. Ce, Fig. 7C) e TRP (Figura 7D). Este padrão de enriquecimento parece ter sido herdado de um intervalo do protólito granítico onde o maior teor de ETR está relacionado à albitização. No entanto, os teores de Ce são mais elevados no saprólito ferruginoso (Figura 7C).

No furo FD117 a zona de albitização reliquiar no saprólito, com alto teor de $\mathrm{K}$, a razão $\mathrm{La} / \mathrm{Lu}$ (Figura 7E) atinge valores de até 20 . Já nos saprólito ferruginoso, abaixo, essas razões caem para valores entre $<1$ até 5 . Isso mostra a tendência de lixiviação dos ETRL em relação aos ETRP, porém nos níveis com maiores teores, o componente dos ETRL parece mais preponderante. Ou seja, sugere-se que a elevação da razão La/Lu no saprólito mosqueado ferruginoso e caulinítico, a partir do saprólito ferruginoso abaixo, deve ser uma feição herdada do intervalo de protólito de rocha granítica mais alcalina.

Amostras de latossolos, colúvios ferruginosos e colúvios quartzosos foram analisadas para comparar a distribuição geoquímica da amostra total com a sua respectiva fração granulométrica menor que 80 mesh. Os resultados mostram que o $\mathrm{Fe}_{2} \mathrm{O}_{3}$ se encontra enriquecido na amostra total somente no colúvio ferruginoso devido à maior presença de concreções ferruginosas (Figura 8A). O As e outros metais com afinidade pelo Fe, também se encontram enriquecidos na amostra total do colúvio ferruginoso, o que reflete seu enriquecimento nas concreções de Fe (Figura 8B).

No caso do $\mathrm{Al}_{2} \mathrm{O}_{3}$, a fração < 80 \# é sempre mais rica em todas as amostras devido à maior quantidade de argilas nesta fração comparada com a amostra total (Figura 8C). Os ETR (La, Ce e Lu nas Figuras 8D, E e F, respectivamente), também se concentram na fração $<80 \#$, o que sugere estarem mais associados à fração silte-argila nestas amostras. Portanto a ferruginização não parece exercer influência na concentração dos ETR, pelo contrário, pode estar relacionada à sua depleção no regolito.

\section{COMENTÁRIOS FINAIS}

O uso integrado dos diferentes produtos aerogeofísicos e de sensores remotos identificou diferentes padrões dos perfis lateríticos. Mostra também ser uma ferramenta importante para identificação de áreas potenciais para bens minerais de origem supergênica. Essa asserção é especialmente verdadeira em regiões equatoriais a subtropicais que apresentam espessos perfis lateríticos.

A variação do índice laterítico no granito Serra Dourada indica que este corpo granítico apresenta diversas áreas potenciais com perfis lateríticos bem desenvolvidos. Esta informação permite inferir que o potencial econômico deste depósito se estende para várias áreas dentro deste granito. Isto porque o depósito é caracterizado como de adsorção em argilas (IAD).

A caracterização do perfil laterítico permitiu observar que ocorrem variações químicas e mineralógicas nos horizontes deste perfil. Os maiores teores de ETR estão relacionados à zona saprolítica, com aumento no teor, dos ETRL, à medida que aumenta sua profundidade, embora nesse caso possa também estar influenciado pela ocorrência de remanescentes de zonas de albitização herdadas da rocha primária. Os ETRP apresentam teores maiores no saprólito mosqueado. 
A B C D E
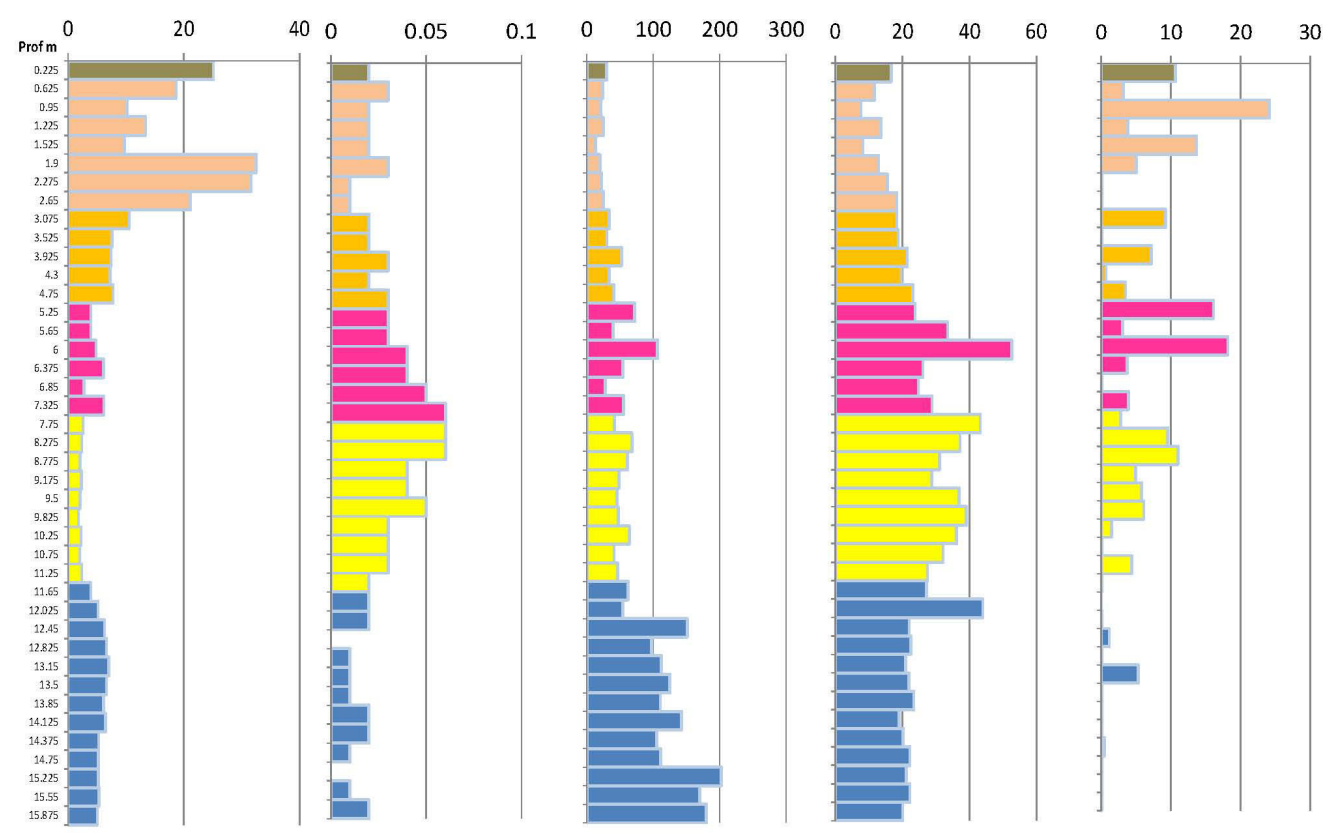

Legenda

Solo húmico

\begin{tabular}{c|c|c|}
$\begin{array}{c}\text { Solo marrom } \\
\text { argiloso }\end{array}$ & $\begin{array}{c}\text { Solo marrom } \\
\text { alaranjado }\end{array}$ & $\begin{array}{c}\text { Saprólito } \\
\text { mosqueado Fe }\end{array}$ \\
\hline
\end{tabular}

Saprólito mosqueado caulinítico

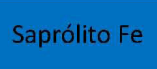

Figura 7 - Distribuição geoquímica no furo de trado FD117. A) $\left.\left.\left.\left.\mathrm{Fe}_{2} \mathrm{O}_{3}(\%) ; B\right) K_{2} \mathrm{O}(\%) ; C\right) \mathrm{Ce}(p p m) ; D\right) T R P(p p m) ; E\right) L a / L u$.

A

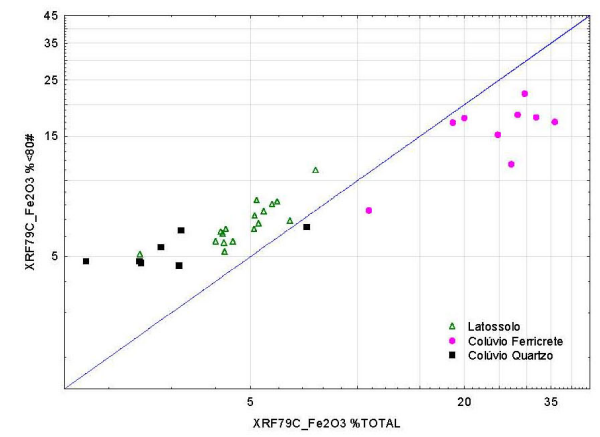

C

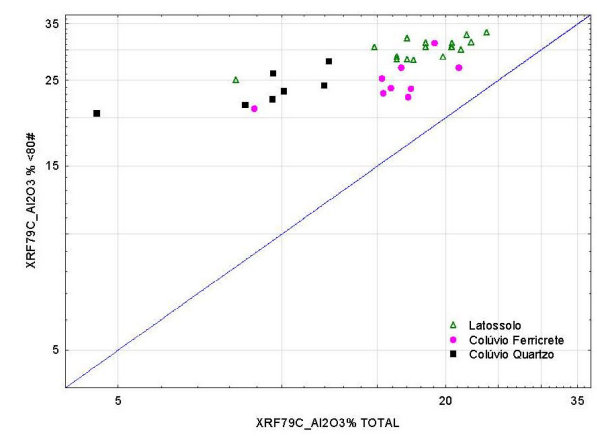

E

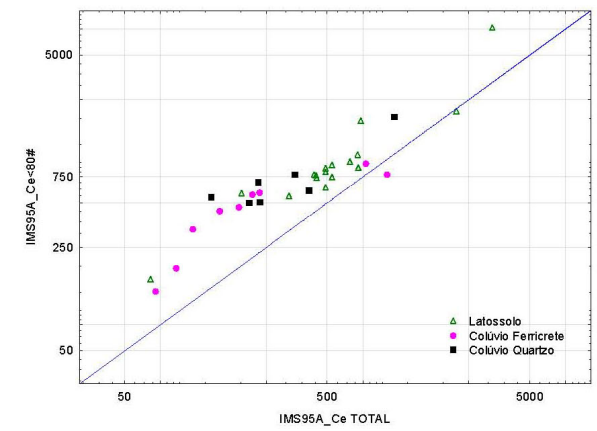

B

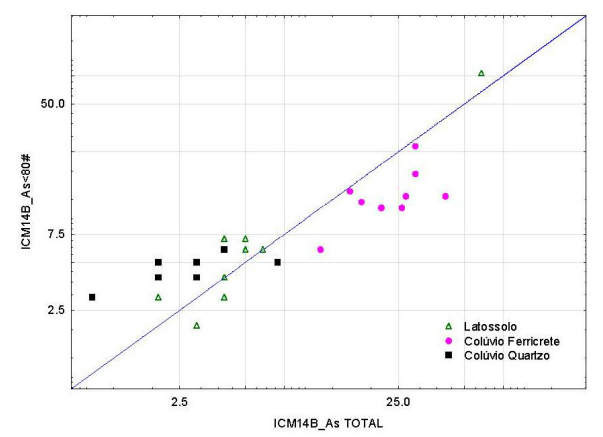

D

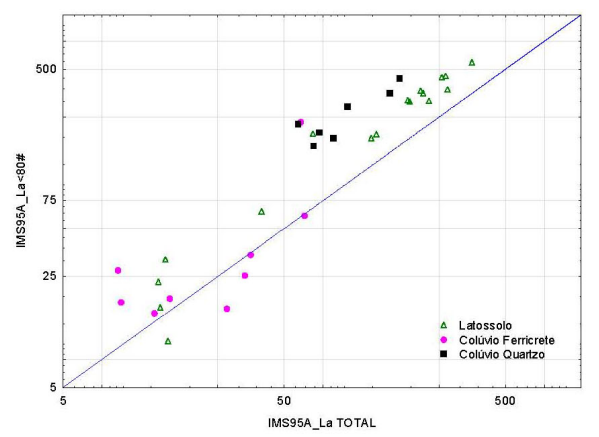

F

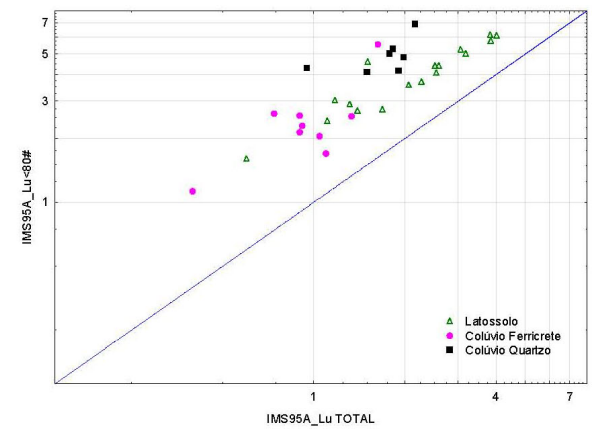

Figura 8 - Distribuição geoquímica na fração < $80 \#$ e amostra total. A) $\mathrm{Fe}_{2} \mathrm{O}_{3} \%$; B) $\mathrm{Al}_{2} \mathrm{O}_{3} \%$; C) As ppm; D) La ppm; E) Ce ppm; F) Lu ppm. 


\section{REFERÊNCIAS}

ALMEIDA, F. F. M.; HASUI, Y.; BRITO NEVES, B. B.; FUCK, R. A. Províncias estruturais brasileiras. Campina Grande. In: SIMPÓSIO DE GEOLOGIA DO NORDESTE, 8., 1977, Campina Grande, PB. Atas [...]. Campina Grande, PB, 1977. p 363-391.

BAO, Z.; ZHAO, Z. Geochemistry of mineralization with exchangeable REY in the weathering crusts of granitic rockas in South China. Ore Geology Reviews, v. 33, p. 519-535, 2008.

$B I L A L, E$. Etude de deux massifs dela province granitique stannifére de l'Etat de Goiás (Brésil) et des formations métasomatiques associées aux minéralisations en Sn et Be. 1991. 382 f. Tese (Doutorado) - ENSM de Paris et Saint-Etienne, 1991.

BRASIL. Ministério de Minas e Energia. Plano Nacional de Mineração 2030 (PNM 2030). Brasília: MME, 2010. 178 p.

CARRINO, T. A.; SILVA, A. M.; BOTELHO, N. F.; SILVA, A. A. C. Discriminação de áreas de espesso regolito do leste do estado do Amazonas usando estatística multivariada, algoritmo hiperespectral e modelagem de dados espaciais. Revista Brasileira de Geofísica, v. 29, n. 1, p. 155-172, 2011.

CHAKHMOURADIAN, A. R.; ZAITEV, A. N. Rare Earth mineralization in igneous rocks: sources and process. Elements, v. 8, n. 5, p. 347-353, 2012.

DARDENNE, M. A. The Brasília Fold Belt. In: CORDANI, U. G.; MILANI, E. J.; THOMAZ FILHO A.; CAMPOS, D. A. (eds.). Tectonic Evolution of South America. Rio de Janeiro: 31st International Geology Congress, 2000. p. 231-263.

DELGADO, I. M. et al. Geotectônica do escudo Atlântico. In: BIZZI, L. A.; SCHOBBENHAUS, C.; VIDOTTI, R. M.; GONÇALVES, J.H. 2003. Geologia, tectônica e recursos minerais do brasil: texto, mapas \& SIG. Brasília: CPRM, 2003. p. 227-259.

EUROPEAN COMISSION. Critical Raw Materials Resilience: Charting a Path towards greater Security and Sustainability. COM (2020), 474 final, Brussels: [S.n.], 2020.

FREYSSINET, P. BUTT, C. R. M.; MORRIS, R. C.; PIANTONE, P. Ore-forming processes related to lateritic weathering. Economic Geology, p. 681-722, 2005.

GOODENOUGH, K. M.; WALL, F.; MERRIMAN, D., 2017. The Rare Earth Elements: Demand, Global Resources, and Challenges for Resourcing Future Generations. Natural Resources Research, v. 27, p. 201-216, 2018.

HERRINGTON, R. et al. Genesis of the Giant Serra Verde Ion Adsorption REE Deposit, Brazil. Viena, EGU General Assembly, Geophysical Research Abstracts, v. 21, 2019.
IZA, E. R. H. D. F. I. Coberturas lateríticas do SW do cráton amazônico: aspectos geofísicos e geoquímicos. 2017. 140 f. Tese (Doutorado n. 140) - Instituto de Geociências, Universidade de Brasília, 2017.

IZA, E. R. H. F.; SANTOS, R. S. V.; CRUZ FILHO, B. E. Integration of multisource data to support the identification of lateritic regolith in Eastern - Bahia, northeastern Brazil. Journal of the Geological Survey of Brazil, v. 3, n. 1, p. 1-24, 2020.

MACAMBIRA, M. J. B. Ambiente geológico e Mineralizações associadas ao Granito Serra Dourada (Extremidade Meridional) - Goiás. 1983. 132 f. Dissertação (Mestrado). Universidade Federal do Pará, Belém, 1983.

MARINI, O. J.; BOTELHO, N. A Província de Granitos Estaníferos de Goiás. Revista Brasileira de Geociências, v. 16, n. 1, p. 119-131, 1986.

MARINI, O. J.; BOTELHO, N. F.; ROSSI, P. Elementos Terras Raras em Granitóides da Província Estanífera de Goiás. Revista Brasileira de Geociências, v. 22, n. 3, p. 61-72, 1992.

PINTO-WARD, C. Controls on the Enrichment of the Serra Verde Rare Earth deposit, Brazil. Thesis (Doctor of Philosophy) - Department of Earth Science and Engineering, Imperial College London, 2017.

PORTO, C. G.; BRANDÃO, F. J. V.; SILVA, A. T. Regolith mapping and exploration geochemistry in the Chapada-Mara Rosa Cu-Au district, Central Brazil. In: INTERNATIONAL GEOLOGY CONGRESS, 35. Cidade do Cabro, África do Sul, 2016.

SANEMATSU, K.; WATANABE, Y. Characteristics and genesis of ion adsorption-tupe Rare Earth Element Deposits. Economic Geology, v. 18, p. 55-79, 2016.

SANTANA, I. V.; WALL, F.; BOTELHO, N. F. Occurrence and behavior of monazite-( $\mathrm{Ce})$ and xenotime-( $\mathrm{Y})$ in detrital and saprolitic environments related to the Serra Dourada granite, Goiás/Tocantins state, Brazil: potential for REE deposits. Journal of Geochemical Exploration, v. 155, p. 1-13, 2015.

TAKEHARA, L.; SHINTAKU, I.; RABELO, D. M.; SILVEIRA, F. V. Avaliação do potencial de terras raras no Brasil. Brasília: CPRM, 2015. 212 p. Informe de Recursos Minerais. (Série Minerais estratégicos, n. 2).

TEIXEIRA, L. M.; BOTELHO, N. F. Comportamento geoquímico de ETR durante evolução magmática e alteração hidrotermal de granitos: exemplo da província estanífera da Goiás. Revista Brasileira de Geociências, v. 36, n. 4, p. 679-691, 2006.

TERRAS raras estratégia para o futuro. Revista de Audiências Públicas do Senado Federal, v. 4, n. 17, set. 2013. Disponível em: http://www2.senado.leg. br/bdsf/handle/id/496343. Acesso em: 21 dez. 2020. 
INFORME TÉCNICO N 18

Brasília, dezembro de 2020.

ISSN: 2448-2242

Publicação on-line seriada

Serviço Geológico do Brasil - CPRM

Disponível em: www.cprm.gov.br

Serviço Geológico do Brasil - CPRM

SBN - Quadra 02 - Bloco H, Ed. Central Brasília, $1^{\circ}$ andar Brasília - DF - Brasil

CEP: 70040-904

Telefone:(61) 2108-8400

www.cprm.gov.br

contatos: seus@cprm.gov.br evandro.klein@cprm.gov.br
Diretor de Geologia e Recursos Minerais

Márcio José Remédio

\section{Corpo Editorial}

Evandro Luiz Klein (Editor)

João Henrique Larizzatti

\section{Revisores}

Evandro Luiz Klein

João Henrique Larizzatti

Normalização Bibliográfica

Nelma Fabrícia da P. Ribeiro Botelho

\section{Editoração Eletrônica}

Marcelo Henrique Borges Leão Nelma Fabrícia da P. Ribeiro Botelho

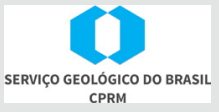

